\title{
Eryngium heterophyllum and Amphipterygium adstringens Tea Ef- fect on Triglyceride Levels; A Clinical Trial
}

\author{
Yessenia García Gómez ${ }^{1}$, Martha Ruth Mendieta Alcántara², \\ Hugo Mendieta Zerón ${ }^{1,3 *}$
}

\begin{abstract}
${ }^{I}$ Faculty of Medicine, Autonomous University of the State of Mexico (UAEMex). Paseo Tollocan $s / n$ Esq. Jesús Carranza. Col. Moderna de la Cruz. C.P. 50180. Toluca, Mexico

2Diabetes Clinic, Regional Hospital "Gral. Ignacio Zaragoza", ISSSTE. General Ignacio Zaragoza 1711, Ejército Constitucionalista, Iztapalapa, 09220, Ciudad de México

${ }^{3}$ Asociación Científica Latina A.C. (ASCILA) and Ciprés Grupo Médico S.C. (CGM). Felipe Villanueva sur 1209 Col. Rancho Dolores CP. 50170 Toluca, Mexico.
\end{abstract}

\begin{abstract}
Herbal medicine represents an alternative for treating dyslipidemia. It has been probed that aerial part of Eryngium heterophyllum, a species of medicinal plant that belongs to the family Apiaceae, reduces cholesterol by $27 \%$ in rats. On the other hand, Amphipterygium adstringens, a Mexican tree exerts a significant hypocholesterolemic effect on rats, lowering cholesterol levels by $31 \%$. The aim of this project was to evaluate the PC-300 tea (Eryngium heterophyllum egelm + Amphipterygium adstringens) against hypertriglyceridemia. It was a non-randomized, descriptive, prospective, longitudinal, and comparative clinical study. Voluntary subjects were assigned sequentially into two treatment groups: 1) fibrate (bezafibrate) $200 \mathrm{mg} /$ day, and 2) PC-300 tea, one cup half an hour before eating. Baseline samples of serum total cholesterol and triglycerides were obtained and measured again after 1 month of treatment. There were 17 patients (males: 6, females: 11) treated with the tea, with a mean age of $49 \pm 15$ years, and 17 patients (males: 8 , females: 9) treated with bezafibrate, with a mean age of $44.7 \pm 13$ years. In the first group, the percentage of triglyceride reduction was $19.7 \%(p \leq 0.05)$, while in the second group, this was $44.8 \%(p \leq 0.001)$. We conclude that consumption of PC-300 reduces triglyceride levels an average of $20 \%$ after 1 month.
\end{abstract}

Keywords: Amphipterygium adstringens; Eryngium heterophyllum egelm; Hypertriglyceridemia; PC-300

Citation: García Gómez Y, Mendieta Alcántara MR, Mendieta Zerón H. Eryngium heterophyllum and Amphipterygium adstringens Tea Effect on Triglyceride Levels; A Clinical Trial. Trad Integr Med 2019; 4(1): 22-27.

\footnotetext{
*Corresponding Author: Hugo Mendieta Zerón

Faculty of Medicine, Autonomous University of the State of Mexico (UAEMex). Paseo Tollocan s/n Esq. Jesús Carranza. Col. Moderna de la Cruz. C.P. 50180. Toluca, Mexico

Tel/Fax: (+52) (722) 2194122 , ext. 157

E-mail: drmendietaz@yahoo.com
} 


\section{Introduction}

Cardiovascular diseases are the leading cause of death worldwide. Among the major risk factors for this health problem, dyslipidemia is highlighted, being the hypertriglyceridemia the most common dyslipidemia in Mexico. Of particular concern, the treatments available for these conditions, while controlling the disease, are accompanied by a number of adverse effects, in addition to the high cost of some of these treatments, which generate long-term treatment dropout. Therefore, the search for novel treatment alternatives is necessary.

Herbal medicine represents an alternative for treating dyslipidemia. Among the options, Chinese groups have tested several composites with one or more plant extracts [1-3]. Unfortunately, the majority of these studies have been conducted in animals. Paradoxically, despite being one of the countries with more biodiversity and with millennial use of medicinal plants, Mexico has published a relatively few clinical scientific papers related with this topic [4,5].

Speaking about successful experiences with herbal medicine, the PC-300 tea (Eryngium heterophyllum and Amphipterygium adstringens) (Figure 1), developed at the University of Chapingo, State of Mexico, Mexico, has the potential to reduce cholesterol and triglycerides [6,7]. Eryngium heterophyllum is a species of medicinal plant native to Mexico that belongs to the family Apiaceae; it was previously known that the aerial part of $E$. heterophyllum reduces cholesterol by $27 \%$ in rats [8]; even more so, E. heterophyllum possesses anti-inflammatory properties [9]. On the other hand, A. adstringens, a Mexican tree known as cuachalalate, exerts a significant hypocholesterolemic effect on rats, lowering cholesterol levels by $31 \%$ [10]. The purpose of this study was to verify the effectiveness of the PC-300 tea compared with bezafibrate in the clinical field.

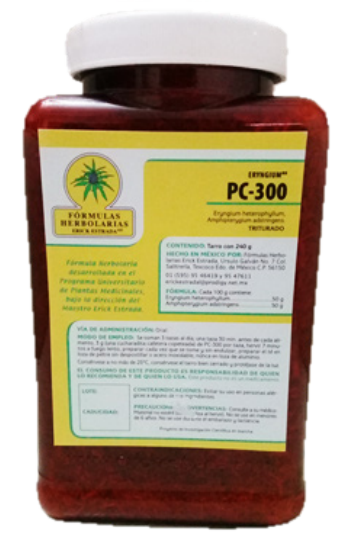

Figure 1. PC-300 tea presentation

\section{Methods}

\section{Place and subjects}

It is a descriptive, prospective, longitudinal, and comparative clinical study with ClinicalTrials.gov identifier of NCT03649269 developed at Ciprés Grupo Médico S.C. (CGM), Toluca, Mexico, from January 2014 to December 2014.

Patients with hypertriglyceridemia, aged $>18$ years and with an educational level at least of primary school were invited to participate in the study. Patients with hepatic disease were excluded, and those missing an appointment during the study were discarded from the final analysis. Voluntary subjects were assigned 
sequentially into two treatment groups: 1) fibrate (bezafibrate) $200 \mathrm{mg} /$ day, and 2) PC300 tea, one cup half an hour before eating.

\section{Plants selection}

The collected plants were cultured in Texcoco, State of Mexico and classified and authenticated by Dr. Erick Estrada Lugo, of the Autonomous University of Chapingo, Mexico. The PC-300 is made with the aerial part of the E. heterophyllum and with the bark of the tree $A$. adstringens. The full sterile bottle weights $240 \mathrm{~g}$ and the percentage of grams per bottle of each species is $50 \%$.

\section{Tea prescription}

The indicated steps for the use of the tea were: put a cup of water to boil, then add a small spoon of tea and let it simmer 4 minutes. Once this is done, it is strained and it can be taken 15 to 20 minutes before breakfast, lunch and dinner.

\section{Sample}

To obtain a $90 \%$ statistical power with an alpha error of 0.05 (two-sided test), to demonstrate an effect of a $15 \%$ reduction in $\mathrm{TG}$ level in patients when received PC-300, 17 patients were needed per group.

\section{Blood samples}

Blood samples (5-ml) were taken after an 8-12-h fasting period in Vacutainer ${ }^{\mathrm{TM}}$ tubes. Serum samples were analyzed for cholesterol $(\mathrm{mg} / \mathrm{dl})$, triglycerides $(\mathrm{mg} / \mathrm{dl})$ and glucose (mg/dl), using appropriate kits (Randox Laboratories Ltd., U.K.) (Vitalab Selectra II,
Vital Scientific, The Netherlands). Sampling times were at baseline and after 1 month with either of the two treatments. All tests were measured according to standardized procedures recommended by the International Federation of Clinical Chemistry and Laboratory Medicine (IFCC) at Laboratorio Artemisa, Toluca, Mexico.

\section{Anthropometric measures}

Patients were measured (m) and weighed $(\mathrm{kg})$ (Obi, México). Body mass index (BMI) was calculated as weight $(\mathrm{kg})$ divided by height (m) squared. Blood pressure was measured with a calibrated sphygmomanometer (Welch Allyn, USA) after 5 min of rest.

\section{Diet}

All of the patients were given a low lipid diet. Calculated kcal were based on ideal weight minus $200 \mathrm{kcal} /$ day if overweight.

\section{Statistics}

Results were expressed as mean \pm Standard deviation (SD). Differences between initial vs. final values were compared with the Mann-Whitney $U$ test. The normality hypothesis was tested using the Kolmogorov-Smirnov test. A $p$ value of $<0.05$ was considered significant. All tests were performed through the SPSS ver. 23 statistical software.

\section{Ethics}

The Ethical and Research Committee of Ciprés Grupo Médico S.C. (CGM), code 2014/02, approved this study. The procedures followed were in accordance with the 
ethical standards of the General Health Law of Mexico and were subjected to the ethical and moral value judgments of the Helsinki Declaration (Fortaleza Brazil).

\section{Results}

There were 17 patients in the group treated with PC-300 tea, mean age $49 \pm 15.9$ years (females: 11, males: 6), and 17 were treated with bezafibrate ( 9 females and 8 males), mean age $44.7 \pm 13$ years. We had 12 dropouts: seven with the tea, and five with bezafibrate.

In the first group, the percentage of triglyceride reduction was $19.7 \%(\mathrm{p} \leq 0.05)$, while in the second group, this was $44.8 \%$ $(\mathrm{p} \leq 0.01)$. In relation to cholesterol, the reduction percentages were $4.8 \%(\mathrm{p} \leq 0.05)$ and $9.2 \%$, respectively (Table 1 ).

In the first group, $15(88.23 \%)$ patients had diminished triglyceride levels and two $(11.76 \%)$ exhibited increased levels. In the second group, the numbers for these changes were 16 (94.11\%) and one (5.88\%), respectively. With respect to cholesterol, nine patients $(52.94 \%)$ had reduced levels (these same patients demonstrated reduced triglycerides) with the PC-300 tea; in comparison, 13 patients (76.47\%) showed this response with bezafibrate.

Regarding gender, in the PC-300 tea group, five males $(83.33 \%)$ and 10 females $(90.90 \%)$ had reduced triglyceride levels. Similarly, in the fibrate group, these percentages were 80 and $100 \%$, respectively.

Table 1. Lipid, glucose and BMI comparison after one month of treatment

\begin{tabular}{|c|c|c|c|c|c|}
\hline & \multicolumn{4}{|c|}{ Group } & \multirow{3}{*}{$p$} \\
\hline & \multicolumn{2}{|c|}{ Tea } & \multicolumn{2}{|c|}{ Bezafibrate } & \\
\hline & Initial & After one month & Initial & $\begin{array}{c}\text { After one } \\
\text { month }\end{array}$ & \\
\hline $\begin{array}{c}\text { BMI } \\
\left(\mathrm{kg} / \mathrm{m}^{2}\right)\end{array}$ & $27.2 \pm 4.2$ & $27.3 \pm 4.1$ & $27.2 \pm 3.8$ & $27.1 \pm 3.6$ & \\
\hline $\begin{array}{c}\text { Cholesterol } \\
(\mathrm{mg} / \mathrm{dl})\end{array}$ & $212.2 \pm 35.5$ & $200.9 \pm 31.9$ & $221.5 \pm 59$ & $189.9 \pm 44.8$ & $\leq 0.05^{* a}$ \\
\hline $\begin{array}{l}\text { Triglycerides } \\
\qquad(\mathrm{mg} / \mathrm{dl})\end{array}$ & $293.8 \pm 142.3$ & $216.3 \pm 117.7$ & $367.5 \pm 141.9$ & $178 \pm 46.8$ & $\begin{array}{c}\leq 0.05^{* \mathrm{a}} \\
\leq 0.001^{* * \mathrm{~b}}\end{array}$ \\
\hline $\begin{array}{l}\text { Glucose } \\
(\mathrm{mg} / \mathrm{dl})\end{array}$ & $170 \pm 93.5$ & $121.7 \pm 28.2$ & $133.3 \pm 80.5$ & $118.6 \pm 56.7$ & $\leq 0.05^{* a}$ \\
\hline
\end{tabular}

BMI: Body Mass Index. a: in the tea group, b: in the bezafibrate group. ${ }^{*} \mathrm{p}<0.05,{ }^{*} \mathrm{p}<0.001$ compared to initial value.

\section{Discussion}

Using herbal alternatives to treat dyslipidemia is not new. For example, Kurian et al. published that the G-400 polyherbal drug (Salacia oblonga root, Tinospora cordifolia stem, Emblica offinalis Gaertn, Curcuma longa, and Gymnema sylvestre) acts as a hypolipidemic agent in patients with diabetes and also attenuates hyperglycemia [11]. 
In the study of E. heterophyllum by Miranda Velásquez [7] the results of chemical reactions for the detection of secondary metabolites suggested the presence of the following types of compounds: alkaloids in the aqueous extract, coumarins only in the aqueous and methanol extract and phenolic hydroxyl (except ethanolic and methanolic extracts) in aqueous extract.

Among other components found in the extracts of E. heterophyllum, the reduction of serum concentrartions of lipids has been explained by the action of saponins [8].

In our study, regardless of treatment type, there was a reduction in triglyceride levels, but the percentage of reduction of triglycerides was higher with the fibrate $(44.8 \%$ $\pm 23.5)$ than with the PC-300 tea $(19.7 \% \pm$ 40.6). Notwithstanding this, supplementations with PC-300 not only reduced triglycerides, but also total cholesterol.

Liu ZL et al reported an analysis of three randomized trials with 170 participants, evaluating Chinese herbal medicines to treat alone or in combination with gemfibrozil hypertriglyceridemia. All three trials reported results in favor of the herbal treatment [12]. In general, China is performing a world leadership novel research based on herbal medicine to lower lipids $[13,14]$. Mexico, with its millennial use of herbology could follow the same trend.

Current treatment strategies directed towards dyslipidemia tend to be limited due to expensive cost of research and sale [15]. By contrast, new insights suggest benefits of natural agents as treatments for metabolic syndrome [16-19]. Following this line, Eryngium heterophyllum as well as Amphipterygium adstringens can be purchased from local markets, but to make it easier, the mix presentation is already prepared and is affordable, economically speaking for low-income populations.

In summary, consumption of PC-300 tea showed a trend primarily in reducing triglyceride levels; however, there is great variability in the percentage of decrease among patients, which could be due to poor treatment adherence and to the different type of dyslipidemia. With this information we postulate that use of the PC-300 tea may be recommended as a monotherapy or in combination with drugs, depending on the degree of lipid increase, age and comorbidities. Specifically, PC-300 should be prescribed for $20-30 \%$ above normal triglyceride values. Of course, when taking the tea there are some side effects, being the main two a decreased consistency of the stools and even diarrhea if taken almost immediately previous to the food ingestion.

A limitation of the study is the low number of patients; this is explained in part due to the withdrawal of Bezalip ${ }^{\text {TM }}$ (Roche) (bezafibrate) from the Mexican market, the drug with which we began medical treatment in one of the groups. However, a clear advantage of the PC-300 tea is its cost and the absence of collateral effects. The price of a bottle of $150 \mathrm{~g}$ of PC-300 tea is of 6.5 US \$ and lasts three months, this mean a cost of $2.1 \mathrm{US}$ $\$$ per month. By contrast, the monthly cost with Bezalip (bezafibrate) is of 24.6 US \$, 
with Controlip (fenofibrate) is 35.3 US \$ and with Lopid (gemfibrozil) it is 48.4 US \$.

We can conclude that the PC-300 tea can contribute to the lipid profile control with a reduction in the TG levels by about 30\% within one month after beginning this treatment. Further study should be conducted on the long-term effect of the tea tested on larger populations.

\section{Funding}

This work was partially funded by Ciprés Grupo Médico S.C. (CGM).

\section{Conflicts of Interest}

None.

\section{Acknowledgment}

None.

\section{References}

[1] An Y, Liu X, Qian Q, Zhang D, Li Y, Gao X. Triglyceride accumulation: inhibitory effects of tangzhiqing for.mula. Altern Ther Health Med 2013;19:20-29

[2] Hirotani Y, Okumura K, Yoko U, Myotoku M. Effects of Gosha-jinki-gan (Chinese herbal medicine: NiuChe-Sen-Qi-Wan) on hyperinsulinemia and hypertriglyceridemia in prediabetic Zucker fatty rats. Drug .Discov Ther 2013;7:105-108

[3] Liu T, Yang LL, Zou L, Li DF, Wen HZ, Zheng PY. Chinese medicine formula lingguizhugan decoction improves beta-oxidation and metabolism of fatty acid in high-fat-diet-induced rat model of fatty liver disease. Evid Based Complement Alternat Med .2013;2013:429738

[4] Calzada F, Yépez-Mulia L, Tapia-Contreras A. Effect of Mexican medicinal plant used to treat trichomoniasis on Trichomonas vaginalis trophozoites. J Ethnophar.macol 2007;113:248-251

[5] García-Sánchez F, López-Villafranco ME, Aguilar-Rodríguez S, Aguilar-Contreras A. Etnobotánica y morfoanatomía comparada de tres especies de Tagetes que se utilizan en Nicolás Romero, Estado de México. Bot Sci .2012;90:221-232
[6] Estrada Lugo E. ed. Plantas medicinales de México. 2nd .ed. Universidad Autónoma Chapingo, Chapingo 1995

[7] Miranda Velásquez LG. Actividad Hipocolesterolémica de plantas de uso etnobotánico en México. [PhD thesis]. .Universidad Autónoma de Nuevo León, Mexico 2010

[8] Astudillo Vázquez A, Ortega Delgado ML, Hernández Xolocotzi E, Estrada Lugo EIJ, Ramírez Torres L. Estudio químico-farmacológico de Eryngium heterophyllum Engelman (yerba del sapo), relacionado con la pre.vención de cálculos biliares. Agrociencia 1985;60:7-19

[9] Carreón-Sánchez R, Marroquín-Segura R, Mora-Guevara JLA, Valadez-Sánchez CS, Flores-Cabrera Y, Flores-Pimentel M, et al. [Study of ethanolic extract of Eryngium heterophyllum (herb frog). To make sure its hypoglycemic and anti-inflammatory activity]. Rev .Mex Cienc Farm 2013;44:41-45

[10] Mata R, Calzada F, Navarrete A, del Rio F, Delgado G. Long-chain phenols from the bark of Amphypterygium .adstringens. J Ethnopharmacol 1991;34:147-154

[11] Kurian GA, Manjusha V, Nair SS, Varghese T, Padikkala J. Short-term effect of G-400, polyherbal formulation in the management of hyperglycemia and hyperlipidemia conditions in patients with type 2 diabetes .mellitus. Nutrition 2014;30:1158-1164

[12] Liu ZL, Li GQ, Bensoussan A, Kiat H, Chan K, Liu JP. Chinese herbal medicines for hypertriglyceridaemia. .Cochrane Database Syst Rev 2013;6:CD009560

[13] Xia X, Weng J. Targeting metabolic syndrome: candi.date natural agents. J Diabetes 2010;2:243-249

[14] Zhang SJ, Cheng ZX, Lin YW, Qin J, Cheng YH, Liu SL. [Effection of compositie salviae dropping pill on hyperlipemia patients with phlegm and blood stasis syndrome]. Zhongguo Zhong Yao Za Zhi 2017;32:440.443

[15] Ahn CH, Choi SH. New drugs for treating dyslipid.emia: beyond statins. Diabetes Metab J 2015;39:87-94

[16] Kianbakht S, Dabaghian FH. Improved glycemic control and lipid profile in hyperlipidemic type 2 diabetic patients consuming Salvia officinalis L. leaf extract: a randomized placebo. Controlled clinical trial. Comple.ment Ther Med 2013;21:441-446

[17] Phunikhom K, Khampitak K, Aromdee C, Arkaravichien T, Sattayasai J. Effect of Andrographis paniculata extract on triglyceride levels of the patients with hypertriglyceridemia: a randomized controlled trial. J .Med Assoc Thai 2015;98 Suppl 6:S41-16

[18] Dadjo Y, Panahi Y, Pishgoo B, Sahebkar A, Taghipour $\mathrm{H}$, Akbari A, et al. Effects of supplementation with Heracleum persicum fruit extract on serum lipids in patients undergoing coronary angiography: a pilot trial. .Phytother Res 2015;29:141-143

[19] Tariq S, Imran M, Mushtaq Z, Asghar N. Phytopreventive antihypercholesterolmic and antilipidemic perspectives of zedoary (Curcuma Zedoaria Roscoe.) herbal tea. Lipids Health Dis 2016;15:39. 